Conservation and Society 7(3): 165-175, 2009

$\underline{\text { Article }}$

\title{
'A Disgrace to a Farmer': Conservation and Agriculture on a Nature Reserve in Islay, Scotland
}

\section{Andrew Whitehouse}

\author{
Department of Anthropology, University of Aberdeen, Aberdeen, United Kingdom
}

E-mail: a.whitehouse@abdn.ac.uk

\begin{abstract}
This article is an investigation into contestations about the landscape of Loch Gruinart, a nature reserve managed by the Royal Society for the Protection of Birds (RSPB) on the Scottish island of Islay. Farmers argued that the low-lying areas of the reserve should have been farmed more intensively to support higher numbers of geese, which farmers disliked because they caused damage to their own grass crops. Instead, the RSPB managed the land to support wetland species through less intensive agricultural practices and by flooding fields. The article takes a symbolic approach that focuses on the ambiguity of Loch Gruinart as both a farm and nature reserve. It is argued that this enables the reserve to be used as a metaphor of relations between conservation and farming. The article demonstrates how farmers used the reserve both to situate themselves and to claim that the reserve was not a real farm. In response, RSPB staff argued for the logic of their management and advocated education and community involvement as a means to help farmers understand their aims. Such controversies, it is argued, are a consequence of conservationists' attempts to bring non-humans into the political arena and can thus be seen as essential to the integration of conservation into Islay rather than inimical to it.
\end{abstract}

Keywords: anthropology, contestation, farming, Islay, landscape, local communities, RSPB

DOI: $10.4103 / 0972-4923.64733$

\section{INTRODUCTION}

Conservationists have sometimes found themselves in dispute with local communities, and the principle of consensual rather than coercive conservation has thus emerged as a central concern of contemporary conservation (Campbell 2005: 302303). ${ }^{1}$ But what is happening when conservation organisations are in dispute or disagreement with local people? Whilst each debate is distinctive, there is a need to explore how such contestations can be examined and how a more general understanding of the politics of conservation can emerge from an analysis of the particular. Anthropological approaches to conservation have necessarily and productively been focussed on the particular and herein I provide a further exemplification through a study of debates surrounding Loch Gruinart, a nature reserve in Islay, an island in western Scotland. The reserve is owned and managed by the Royal Society for the Protection of Birds (RSPB), a large British conservation charity.

My approach to research differs somewhat from many other anthropological enquiries into conservation issues because it was, from the outset, focussed on relations between conservation organisations and farmers rather than a concern for how conservation policies and activities impact upon a group of people that the anthropologist works with. In other words, this was always the study of a relationship rather than a study of a people and the external factors that affect their lives. As such, the aim has been to explore how this relationship developed and what ideas and assumptions underpinned the debates that emerged. This shift in focus towards the dynamics of relations over time thus draws attention to the often shared ideas that underpin differences and contestations rather than emphasising the effects of impersonal political 'forces' on people. Following from many classic studies of British rural communities (Cohen 1982a, 1985, 1987; Littlejohn 1963; Macdonald 1997; Mewett 1982a, 1982b; Phillips 1986; Strathern 1981, 1984) I take a symbolic approach to exploring these relations that examines how groups and individuals (Cohen 1996; Rapport 1993) situate themselves in relation to one another through the use of symbols. Furthermore, my interest is in symbols that are not so much shared within the community but that represent relations between farmers and conservation organisations. ${ }^{2}$ Loch Gruinart is just such a symbol, which draws its symbolic

Copyright: (C) Andrew Whitehouse 2009. This is an open access article distributed under the terms of the Creative Commons Attribution License, which permits unrestricted use and distribution of the article, provided the original work is cited. 
freight through its ambiguous status as both farm and nature reserve. In this article I describe the ways in which farmers and the RSPB draw on this ambiguity to situate themselves and others and to debate the ongoing relations between the activities of farming and conservation in Islay. My contention is that, in order to understand debates between conservationists and others, one can productively consider the symbolic elements through which these debates are conducted. This is not to say that such debates are merely symbolic but that the employment of symbols is integral to an understanding of how people and groups situate themselves in relation to one another and to their environment.

\section{THE LANDSCAPE AND CONSERVATION OF LOCH GRUINART}

Conservation organisations have long been interested in Islay because the island, with its diverse habitats and relatively extensive agriculture, is very important for various species that are rare elsewhere. But they only became actively involved in island life after the Wildlife and Countryside Act was implemented in 1981. The new legislation, particularly the additional protection given to Sites of Special Scientific Interest (SSSIs), led to a number of disputes on the island during the 1980s, including a famous conflict over peatlands that were to be developed to supply the island's illustrious whisky industry. Farmers and landowners often perceived these conservation designations as constraining on their ability to produce from their land and so they could be seen to threaten their independent livelihoods. However, the biggest conservation issue in Islay has always been 'the goose problem', a dispute that had a clear influence on the development of debates about Loch Gruinart. Between October and April, Islay is visited by large numbers of geese. Most belong to two taxa: the barnacle goose and the Greenland white-fronted goose. The geese bothered many farmers because they caused damage to their grass crops, increasing their costs and reducing productivity (Elliott 1989; Ogilvie et al. 1999; Patton and Frame 1981; Whitehouse 2004). But, although the geese were very numerous in Islay, they were low in number globally and so conservationists had long been concerned to protect them. This protection arrived in 1981 with the Wildlife and Countryside Act, although under the Act it was also possible for farmers to apply for licences to shoot geese if they were causing damage to their crops. So the geese came to be classified ambiguously in law as both a protected species and a potential agricultural pest. This dual classification created tensions between the conservation organisations who wanted to protect the geese, and farmers who suffered financially because of them. Since 1981 there have been various attempts to resolve these differences, usually involving the government's conservation body Scottish Natural Heritage $(\mathrm{SNH})$ or their predecessor organisations, the Nature Conservancy Council (NCC) and the Nature Conservancy Council for Scotland (NCCS). The RSPB reserve at Loch Gruinart was an integral part of the earliest attempts to do this.
The RSPB first established a permanent presence on the island in 1983 when they purchased the 1600-hectare Loch Gruinart reserve from Islay Estate. The reserve was centred on the large and productive farm at Aoradh and, as well as agricultural land, the farm included areas of moorland, woodland and boggy wetlands. The initial aim of management was to act as a sanctuary area for geese and this helped the RSPB to, controversially, obtain a grant from the NCC (i.e. the government) towards the purchase. It was hoped that the reserve and other areas within the sanctuary zone would ease the pressure on farmers elsewhere, who would be able to shoot and scare geese from their land under licence. This system operated for much of the 1980s but met with little success. Despite the shooting, the geese increased in number and spread to most farms on the island. The sanctuary system was disbanded in 1992 and was replaced with a scheme that compensated all farmers throughout the island. Because the Loch Gruinart reserve was no longer the lynchpin of the management of geese on Islay, the RSPB changed the way they managed some of the land on the reserve. The low-lying flats were flooded and patches of rough vegetation were allowed to develop. This contrasted with the green and well-drained fields of neighbouring farms on the flats, where the farmers grew good crops of barley and silage to feed their cattle during the winter.

Below I describe some of the concerns that farmers in Islay had about changes they perceived to have taken place at Loch Gruinart since the RSPB had acquired the reserve in 1983, differences analogous to those perceived in the contrast between the reserve and neighbouring farms. Although this involves drawing attention to criticisms that were made of the RSPB, my intention is not to offer a critique of their ideas or practices but to understand why others might be critical of them and how a nature reserve became an important and useful part of local debates about conservation and farming in Islay. By examining how both farmers and RSPB staff described their opinions of the reserve and its management I explain why the differences noticed by farmers sometimes angered them and also how these differences were useful as well as problematic for the RSPB. In this sense, my concern is to examine the use of the reserve as a metaphor of the relationship between conservation and farming. People employed the reserve to situate themselves in terms of this relationship and to think about how it should best proceed. By situating themselves, people are marking differences and similarities with others. This can classically involve a conceptual boundary (Cohen 1985) marking difference as a discontinuity but difference can also be perceived as more subtle continuities that are more malleable (Bateson 1979: 45-49; Phillips 1986).

The landscape of the reserve is incorporated into debates about land, how it should be used and who should have influence over these uses. This incorporation is physical in the sense that landscape is physically produced with strategic aims in mind, but it is also symbolic in the sense that it can embody social and ecological relationships and ideas about how these should proceed. Whilst an emphasis is placed more 
on these symbolic uses of landscape, this does not preclude a concern with people's physical interactions with the land and their environment because the discursive use of landscape is grounded in individuals' experiential engagement with their physical environment (Bender 2001: 4). It is, in the sense of environment as 'that which surrounds' (Ingold 2000: 20), an environmental interaction in itself. I thus have no intention to draw a sharp distinction between landscape as material and landscape as idea, representation or view. My focus is on how the landscape of Loch Gruinart is produced and utilised both physically, as a habitat for wild and domestic species, and how it is produced and used symbolically within discourses about conservation and farming in Islay. RSPB staff physically engage with the landscape for certain ends but also, quite consciously, produce it as representing certain ideas that can be read from the landscape and utilised politically.

It should also be emphasised that, although my interlocutors will be described as farmers and conservationists, their comments are distinctly personal and contextual. Following Mazzullo (2005), I do not intend to reduce viewpoints to being simply representative of a particular social group so, whilst many farmers complained to me about the way the reserve was managed, they did so in idiosyncratic ways and in response to the context of our discussion. The reserve was thus employed symbolically within personal situating practices, providing a means by which individuals expressed differences between themselves and others and towards which they were oriented in contrasting and context-related ways. This bears comparison with the classic symbolic approach to British communities adopted by Cohen and others (Cohen 1982b, 1985, 1987; Mewett 1982b; Phillips 1986; Strathern 1984). In this, symbols are shared by a group but are ambiguous, allowing members to appreciate the meanings of the symbol in their own personal way. Such features become a 'boundary-expressing symbol' (Cohen 1985: 15) and serve to differentiate one group from another. Symbols can thus be utilised to express belonging to a group but they also serve to express individuality: the particular circumstances and quirks of each person (cf. Cohen 1996). Individuals incorporate symbols into their loops of thought and dialogue to personalise their 'world views' (Rapport 1993).

One of the key symbolic capacities of the reserve emerges through its inevitably ambiguous representation of 'nature' but what distinguishes this example from much of the anthropological literature about the representation of nature within conservation is that the RSPB were not trying to conserve nature as wilderness, with all its problematic associations (Cronon 1996). They made no attempt to exclude human activity from the landscape but instead actively managed the land in apparently similar ways to neighbouring farmers. This is normal within the UK, where it is assumed that landscapes are almost invariably 'cultural' and the products of a lengthy history of manipulation (Evans 1997: 261-268; Jedrej and Nuttall 1995: 138; Smout 2000; Warren 2002: 1316). As illustrated below, this still involves looking to the past to evaluate how landscapes should be, but it is understood that the special qualities that conservationists seek to protect within the UK require human intervention, often through agricultural activities, rather than exclusion (cf. Jedrej and Nuttall 1995: 138-139; Milton 1996: 124). To this end, Loch Gruinart was actively managed through agricultural techniques and the RSPB employed people with farming backgrounds to carry out these practices.

So here was a nature reserve that apparently drew on historical patterns of local human use in its management and yet contestations over these management practices still emerged. My approach to this is not to emphasise a 'culture clash' between conservation and 'local people', in which conservation has negative impacts on the people anthropologists have often tended to be most concerned with (Einarsson 1993; Novellino 2003; Nygren 2003). Much of the anthropological literature on conservation draws on the conflict suggested in the anthropology of development between scientific and local knowledge (Hobart 1993) and also by implication the agency of certain discourses (Brosius 1999). One could easily conceive of the relations between conservationists and farming people in Islay as predicated on conflicting bodies of knowledge, values, and practices. At certain moments this was indeed how it was represented by my informants and through the local media. But because 'environmental debates are not merely zones of contestation but zones of constantly shifting positionality' (Brosius 1999: 283 ) it can prove fruitless to frame any such contestation in terms of a clash between contrasting cultures or bodies of knowledge. This is particularly true in Islay, where shifting positionality is grounded in shared ideas about how difference is generated and changes happen.

My approach instead has been to focus on the social and ecological relations of farmers and conservationists in Islay and to consider how these are seen within each group. This necessitates a concern with those who work 'on the ground' in conservation, such as nature reserve wardens and local representatives of conservation bodies. There is still surprisingly little anthropology addressing the perspectives of those who work in conservation and much of that focuses on campaigning activists (Satterfield 2003) or on senior figures (Milton 2000) rather than those who work in nature reserves or parks. Attending to such people, whose work often has to be pragmatic and sensitive to local situations, is critical if anthropologists are to examine efforts at participatory conservation (Campbell 2005) or to understand how contestations develop. This is particularly so in places like Islay, where nature reserves are not very different in their appearance and ecology to other types of land, such as farms and estates. Whilst it is ostensibly a success story for conservation if biodiversity is not ghettoised within reserves and parks, this can present conservationists with significant problems in justifying their own activities and maintaining their distinctiveness. Presented below is a dialogue of contestation but also a 'shared conversation around values' (O'Neill 2005: 479) that emerged through interviews I conducted with farmers and conservationists and through the pages of the local 
newspaper, the Ileach. Prior to this I provide further details about both farming and farmers in Islay.

\section{FARMING IN ISLAY}

Farming in Islay is more diverse than in other parts of the Hebrides. Its fertile soils allow for full-time livestock farming, as well as for part-time crofting and small-holding. The people who farm in Islay are also diverse. There is a long history of people coming from the Scottish mainland to the island to farm, and over recent decades many farmers have come from England too. This means that, when one talks of Islay farmers, one is referring to a mixture of incomers and locals and those that have been born and bred on the island are often the offspring of incomers. Many farmers in Islay became owner-occupiers between the 1970s and 1990s as a result of the break-up of some of the larger estates, although many others remain as tenants. Whilst there is a long history of tenancy the upheavals of the $19^{\text {th }}$ century clearances affected Islay much less profoundly than they did other parts of the west Highlands (Storrie 1981; Richards 2000).

In the second half of the $20^{\text {th }}$ century the trend in farming in Islay was, like other parts of Britain, towards specialisation in either beef or dairy cattle, usually together with sheep. Agriculture also intensified during this period, but this was rarely on a comparable scale to lowland farms. This intensification had complicated effects in relation to birds. Geese adapted well to the productive permanent pastures that began to predominate, but species that prefer more extensively farmed or less well-drained conditions, such as corncrake, chough and waders, fared less well. Whilst Islay remained important for these birds, conservationists became concerned at the effects that agricultural changes had upon them. Occurring alongside the trend towards specialisation was a movement towards diversification away from agricultural activities and into areas such as accommodation for tourists. Conservation came to provide a significant source of income for many farms, through compensation payments for goose damage or from management agreements for SSSIs. Despite the growing significance of non-agricultural income and the considerable overlap in the activities of both farmers and conservationists, Islay farmers normally expressed a practical and aesthetic view of farming landscapes rooted in a concern with productivity and improvement rather than in terms of their value for conservation and tourism. What this entailed was a desire from farmers to see that labour is evident in the landscape of a farm and its products. As one farmer put it, "One of the biggest compliments we've ever had was when a friend of ours passed by the farm and he said to us, 'I know there's definitely someone living up there." Farmers wanted to show in the land that they are working and that they appreciate the values of a good farm that the activity of farming entails (Whitehouse In print). Although conservation became an important source of income for farmers, the actions of conservation organisations and the geese for which they were held responsible could conflict with this productive ethic.

The heterogeneity of farmers and farming in Islay raises important questions about differentiating change and how this is perceived, questions that have significant implications for attitudes towards conservation. Change was widely assumed to arrive in Islay from outside and so dealing with novelty was often a case of dealing with the wider world (Whitehouse In print). Innovation was important and incoming farmers often brought with them new methods that eventually caught on with existing farmers. Even welcome developments still needed to be carefully negotiated but there was a widespread perception that changes had become more difficult to deal with, as the locus of change grew ever more distant and impersonal. For example, whilst farmers previously had to negotiate with the estate owner whose land they farmed, they began to have to deal with the demands of the seemingly more detached bureaucratic regimes in London or Brussels. When conservation arrived in Islay in the 1980s it was readily incorporated into this way of thinking about change and its relations to the wider world. This in part explains the widespread anxieties about conservation amongst farmers. Indeed, much of the history of conservation in Islay has involved attempts to make conservation seem more local and thus more negotiable.

\section{ACTIVELY RUN DOWN}

In 1997 a letter was published in the Ileach, from 'A very irate farmer' expressing reservations at the turn of events since the RSPB's takeover of Aoradh, particularly in light of money that was given for its purchase by the NCC: ${ }^{3}$

As a farmer in Islay I am unable to understand why the RSPB was able to procure such a large proportion of the purchase price for Aoradh Farm from the public purse? [sic]

I understand that one of the main reasons given by RSPB and SNH was to help the farmers on Islay cope with the escalating goose population. I find this difficult to understand when it looks as if the farm is being actively run down, with the quality of grass on which the geese are meant to feed being so poor. The farm is a disgrace to a farmer.

The RSPB may have as many geese roosting on their farms as in previous years but they used to feed them as well. Now they have to spread out all over the rest of the island to fill their bellies on well-managed costly grass. Like most organisations farmers are accountable for every pound they receive from the public purse.

The farmers in Islay are all up in arms about the escalating goose population. One way to help a little would be to have 400-500 acres of good grass on Aoradh, the purpose for which the subsidies were given (and continue to be given) from the public purse.

Are readers happy with what the government is doing with their money?

Two-and-a-half years after this letter was written I spoke to Iain Taylor, ${ }^{4}$ a farmer who was concerned about the increasing numbers of geese coming on to his land:

A big knock on effect is the flats, the RSPB reserve. I'm not 
anti-RSPB or anything like that-I'm just going on what I can see. My father worked at Aoradh in 1958, 1959. That was all green ground in the Sixties and they'd get big silage cuts and the geese would come in and they'd land there and they'd stay there; they didn't disperse the same. You see all these fields flooded and that won't grow grass to feed geese. It'll hold plenty of waterfowl but it'll never hold the grass to hold the geese. The RSPB bought Aoradh from Islay Estates and their remit was to grow the grass to hold the geese...

And they changed their policy?

'Well, I wouldn't say they changed their policy; it's just that certain people in the management of the RSPB have a bigger clout and they want more wetlands than they do geese but it's a knock on effect. We have a lot more geese.'

When I talked to another farmer, Brian MacAskill, he told me that he got on well with the RSPB staff but was concerned that the Society had broken agreements in their management of the reserve:

'They bought Aoradh for geese but then they flooded it and let rubbish grass take over. A lot of public money was given to buy that land and it was given in order for it to be a sanctuary for geese. There should be some sort of agreement that makes them stick to what they said they'd do. With an Environmentally Sensitive Area (ESA), ${ }^{5}$ the farmer has to stick to what's in the agreement and if they changed they wouldn't just lose the money, they'd be fined. But they've completely changed the farming policy to attract wading birds and ducks. They should get their money taken off them or they should put in younger grass.'

Two related concerns about the reserve emerge from the quotations above. The first is that the farm was 'being actively run down' by the RSPB who were letting 'rubbish grass take over,' which in turn meant, 'it'll never hold the grass to hold the geese'. It was suggested that the RSPB were reneging on an agreement to farm the land principally to hold geese and prevent them from spreading out to other farms on the island where they could cause damage to the "well-managed costly grass".

The opinion that the reserve was being farmed badly could potentially be related to another aspect of the RSPB's work in Islay. Graham and Ellen Campbell told me what they thought of the RSPB:

'The RSPB seem to think that we're all bad farmers and that everyone should farm like they do, but when you look at their farm, they're shocking. They just grow weeds and this bad farming isn't the way forward for wildlife. They used to have good stock there when Douglas, who's a friend of ours, worked as stock manager. He used to breed very good animals, but he's moved off to a better job up north.'

The RSPB had been keen to encourage farmers to emulate the methods employed at Loch Gruinart, but given such a derisory opinion of their farming this seemed either offensive or simply laughable to Graham and Ellen.

Even farmers who were overtly farming for wildlife were conscious of the widely held antipathy toward the RSPB's methods. Anthony Scott was developing a scheme for birdfriendly farming in association with the RSPB and he thought this would impress farmers in a way that the RSPB's efforts on their own reserve never could:

'The RSPB say they want people to farm like them, but farmers just see it as bad farming. If they drive through the $R S P B$ reserve they see something that's different to what they do but with my farm they'll see something more similar.'

The condition of the land on the flats had further implications, particularly for a retired farmer such as Archie Baxter, who had a great knowledge of how the modern landscape was created:

'If it was a tenanted farm they would have been thrown out by the landowner by now it's so bad... There are too many cattle out-wintering in too small an area where they're up to their knees in mud. I don't mind the area that they've flooded. They've obviously increased the number of ducks there. But I don't like what they've done to the flats. Before they came that area was a good farm with a lot of wildlife. And if you look across at Craigens there's a farm - a good farm - which is still in rotation. When you consider all the work that went into creating those flats back in the $18^{\text {th }}$ century it's a great shame. It's the easiest thing in the world to destroy something, but the hardest to create.'

Don Currie and his wife Margaret, an elderly farming couple, connected their opinion that the RSPB reserve was in poor condition with the RSPB's competence in land management. When I asked them what they thought of the RSPB they made the following points:

'The RSPB don't believe in controlling anything. There's a sea wall at Gruinart, which had a rabbit warren in it. The RSPB didn't control the rabbits and eventually the sea wall collapsed and flooded the cottage on the flats... The RSPB haven't got much of a clue about farming and they've never given the farm manager enough influence. They expect to get a crop from fields, which are flooded throughout the winter, which is ridiculous. Those used to be good arable fields. They're thoroughly out of their depth.'

Although the RSPB might have appeared incompetent at farming, it was questioned how significant this was to such a large organisation. I asked Gilbey MacArthur, a crofter, for his opinion of the reserve:

' What the RSPB do on their reserve isn't really farming because they're not doing it to make money. They lost something like eighty thousand pounds last year, but an organisation like that can absorb that sort of loss easily.'

Tom Wilkie farmed near the Loch Gruinart reserve and, 
like the RSPB, he was an incomer to Islay from England. I asked Tom what he thought of the RSPB and, after a pregnant pause, he said:

'When I came to Islay I took on a guy who'd been here for twenty or thirty years and I learnt a lot from him about how to do things. The RSPB asked around and then did the exact opposite. They seem to think that farmers are only interested in farming for money but they live in the countryside because they like it. Farming on the flats is something you have to work at with the crops, but you can do it.'

The foregoing illustrates the widespread opinion amongst Islay farmers that the RSPB reserve was a bad or poorly managed farm, if indeed it could be regarded as a farm at all. Flooded fields, extensive rushes, weeds and bad grass were all signs of bad farming and neglect, and most had striven for decades to get rid of such things. What is notable in all the above is that farmers connected the idea that Loch Gruinart was a bad farm with aspects of their own experience and that these connections served to contrast the RSPB with 'real' farmers. In particular, farmers were considering the sorts of political and economic relationships, particularly with government and the landowning estates, that both they and the RSPB had been involved with and how these relations shaped the divergent landscapes they perceived and produced.

Farmers had for many years been given grants and subsidies by the government, normally with the express aim of encouraging the farmer to carry out certain practices, farm in a certain way and produce specific products in specific quantities. More recently farmers had become accustomed to environmental agreements for ESA schemes or NCC/SNH management agreements in which they consented to farm using methods that maintained or enhanced wildlife and their habitats. In such cases the farmers thought that if they broke agreements then the payments could stop and they might be fined. Whilst the RSPB never signed an agreement to manage Loch Gruinart predominantly for geese, they were given a grant by the NCC towards the purchase of the farm as a means of helping to secure the local populations of geese. Many farmers clearly considered that the poor state of the land indicated that this role was no longer one of the RSPB's priorities. The apparent inaction against the RSPB for this change of plan was seen by Brian MacAskill and the anonymous letter writer to represent a rather different relationship with the government, and particularly $\mathrm{NCC} / \mathrm{SNH}$, than was experienced by ordinary farmers. The RSPB appeared to have been trusted to such an extent by the government that they did not need to be accountable for their use of public money, and this during a period when government 'policing' of farmers was perceived to have risen inexorably.

Like the NCC, Islay Estate had envisioned the reserve primarily as a goose sanctuary that eased the pressure on the island's farmers but the state of the land appeared to contradict this. In his statement, Archie Baxter argued that if the RSPB had been tenant farmers, as he had been, then "they would have been thrown out by the landowner by now it's so bad". Whilst this implies an acknowledgement of the greater freedom the RSPB had as owners of their land, this did not prevent Archie from making the comparison with the more constrained position of a tenant. The implication in the comments of both Archie and Iain Taylor was that the RSPB were indulgent in their own concerns in spite of both the wishes of Islay Estate, which had sold them the land, and of other farmers, an indulgence that was out of the question for a tenant. Gilbey MacArthur indicated that such extravagance was beyond the means of small-scale local operators because they would be unable to absorb the likely financial loss.

The comment of Tom Wilkie is particularly revealing because he raised the issue of being both an incomer and a farmer in Islay. Tom contrasted the actions of the RSPB to his own behaviour on arrival. He had asked for advice and followed it but "the RSPB asked around and then did the exact opposite." Tom felt that his own behaviour, listening to advice and working hard at farming the flats, was the more appropriate, certainly if he wished to farm successfully but perhaps also if he wanted to integrate into the community and be respected as a farmer. Anthony Scott, another Englishman, believed that the respect he was accorded as a farmer gave him an edge over the RSPB when it came to encouraging bird-friendly farming. To the Curries, the poor state of the RSPB reserve was born of incompetence rather than care and planning. Such negligence had even resulted in a neighbour's cottage being flooded. Views like these meant that when the RSPB suggested to farmers that they take on their methods they were unlikely to get far. In the Campbells' experience this was not even what should be done to encourage wildlife. If a conservation organisation really wants to encourage wildlife then they should employ competent farmers and, as the Curries said, give them some influence.

A number of farmers also made an explicit connection between the state of the RSPB reserve and their experience and knowledge of the past. This was the past when the flats were created in the $18^{\text {th }}$ century and when the drainage was improved in the 1950s. It was also the past when Iain Taylor's father worked at Aoradh and the ground was green and produced big cuts of silage. It might also be the past when Douglas was the stock manager and the RSPB produced some good quality livestock. These were described as times that the RSPB did not have access to, did not know of, or had rejected. The present condition of the reserve and the actions that the RSPB had taken since they acquired the land served, in the eyes of some farmers, to separate the RSPB from what has gone on before and, by implication, from the values and knowledge of good farming and good farmers.

I argue then that farmers made these comparisons between the reserve and their own experience not simply to censure the RSPB but also to separate the RSPB from themselves. Their criticisms and contrasts were ways of saying that the RSPB were not real farmers and their reserve was not a legitimate farming operation. The RSPB's privileged relationship with government and the estates, their apparently disrespectful behaviour as incomers, 
their secure financial circumstances and their separation from the past all characterised them as something other to a proper farmer. And by making this separation the farmers also expressed something about themselves and about their position as good farmers, who were constrained by government and their own financial position, who understood how to behave in a farming community and, above all, who appreciated the values of a good farm in Islay. The juxtaposition of the idea that the RSPB reserve was a bad farm with these farmers' own experiences, circumstances and values served as a means to situate the RSPB outside of a farming identity and the moralities and knowledge this entailed.

There are some broad parallels here between the idea of 'real farmers' and Strathern's discussion of 'real Elmdoners' (Strathern 1982a, 1982b). This case is less about relatedness through blood, as in the case of belonging to 'real Elmdon' families, but to Islay farmers it is still about certain other relations and ideas about how these should be conducted: relations with government and estates, the past, the market and, ultimately, with Islay. Whilst the RSPB might have conducted farming activities at Loch Gruinart, their different relations and values were made manifest in the landscape of the reserve. Farming and conservation were thus symbolic resources as much as activities because they enabled people to think about both social and ecological relations (Cohen 1994: 150). Loch Gruinart, as a farm/nature-reserve, was a metaphor for relations between farming and conservation and thus created further possibilities for people to examine their own social and ecological situations.

\section{MISCONCEPTIONS AND EDUCATION}

None of the above would have come as a surprise to any RSPB staff in Islay because they were well aware of negative local opinions of them and their reserve. Their response to these negative opinions was twofold: firstly, education was required in order to address misconceptions about the aims and activities of the RSPB's management; secondly, the community should have a greater involvement in the running of the reserve. For example, when the likes of 'A very irate farmer' wrote letters to the local newspaper a member of the RSPB staff would normally respond to 'set the record straight'. In that particular case the response came from Matt Davies, the Reserve Manager. After explaining their strategy for management and enumerating the substantial goose counts for the reserve, he concluded his letter thus: ${ }^{6}$

'The RSPB is not running down its farm and the quality of grass that we produce remains high. It is also worth pointing out that the RSPB is even more accountable, not only to $\mathrm{SNH}$ and the Agricultural Department for funds received but also to our 1 million members and our governing Council. The staff at Loch Gruinart is all proud of our farming and conservation achievements to date.'

The RSPB often seemed keen to argue publicly that the reserve was a proper farm, something emphasised on a guided walk I attended led by Anna, the assistant warden. She claimed that the main difference between the RSPB and farmers was that farmers understandably concentrated on maximising profits whereas the RSPB focused on maximising wildlife. Despite the difference in priorities the RSPB were keen to point out the dual nature of Loch Gruinart as both farm and nature reserve. This was an image that they actively created in the landscape, publicised and presented.

I put a number of the criticisms that I had heard from local farmers to the reserve warden, Pete MacLean. Pete's job involved the day-to-day running of the reserve but he also conducted research into choughs and corncrakes. Originally from the north of England, Pete and his wife had worked for conservation organisations in the west of Scotland for several years and his association with Islay stretched back to the 1980s. He explained the shift in priorities in reserve management as follows:

'The geese weren't protected on Islay. When this reserve was bought it was the only place that geese weren't being shot. This was bought as a safe haven and as a safe roost site. Since then the goose scheme has come into effect, which has given 99 percent protection for barnacle and white-fronted geese right across the island. So, as a result of that, goose numbers have increased across the rest of the island, which takes the pressure off a lot of Gruinart as being the only place on Islay where barnacle geese are protected. In the early days of the reserve we were ploughing up fields when lapwings were nesting to reseed them for geese and we turned things like that around so that now, as well as managing for geese, we're managing for breeding waders, corncrake, hen harrier and chough.'

Could you carry more geese if it was managed more intensively?

'We managed much more intensively. When Tom Palmer was the farm manager it was managed much more intensively. The numbers of geese then were the same as they are now... We get thousands of geese every autumn. They all come here. We get eighteen, nineteen thousand geese on this one farm - it is one farm after all. They come in and they eat whatever is there that they can find... Callum Neill ${ }^{7}$ was here last year... He was amazed to see what we were doing here. You can't see it from the road very easily. Basically we've taken the pressure off the flats by improving the hill ground. So now the hill ground supports more grassland, more arable crops, more geese than it used to do. That's taken the pressure off the flats. But we couldn't have corncrakes all down on the flats there if they weren't managing that land... There's lots of geese on the island; there's only eight corncrakes and we've got five of them on our reserve and we have to cater for everything.'

Pete made two points in his explanation of the change in management priorities. Firstly, circumstances elsewhere on the island (the advent of the Islay Voluntary Goose Management Scheme) meant that the need for geese to be prioritised on 
the reserve was lessened. The geese had become protected throughout the island and there was an increase and expansion in the population. Secondly, this change had allowed the RSPB to concentrate on other species, such as corncrakes and breeding waders, as much as on geese. By changing the management of the flats so they were not "ploughing up fields when lapwings were nesting to reseed them for geese" they were maximising their wildlife output. The flats provided for these other important birds whilst habitat management elsewhere was primarily aimed at geese. Large areas of land were improved for this purpose to take "the pressure off the flats by improving the hill ground", which made up for the loss of feeding on the flats. Despite these efforts it was very difficult for the RSPB to increase the numbers of geese feeding on their land any further because at the start of the winter they were inundated with birds. Most of their grass would be eaten before it could recover and even when they had farmed more intensively on the flats they had been unable to hold any more geese because they always moved on to better feeding elsewhere after they had worked their way through the RSPB's grass.

Pete suggested that the reason that the improvements on the hill ground had not been noticed was that these fields were out of sight, whereas the flats could easily be seen from the road. Whilst the flats might be problematic to some farmers, the RSPB still had to farm properly to hold geese and maximise their wildlife output. The reason the RSPB chose to change the management on the flats was because this area had a greater potential as habitat for other priority species, such as breeding waders and corncrakes, than the hill land. Geese will feed on any improved grassland in Islay and this can be created in most situations but on the flats it was possible to manipulate the water levels to create floods and wet ditches, something important when managing for species such as waders and wildfowl.

I commented to Pete that some local farmers were unhappy with the creation of the floods. He responded:

'Yeah, well that's understandable. The history of the site is one of reclamation and that's going back to the 1700s, you know. It used to be a saltmarsh and then it was turned into farmland by Dutch engineers. And Bobby Phillips, the previous farmer here, spent a lot of time keeping his fields nice and green and fertilising them and draining them. And, to a farmer's eyes, his nice green fields were a credit to him, which they were. The fields now are not nice green fields. They've got rushy ditches for nesting lapwings and redshanks and they have wet ditches for nesting lapwings and redshanks... That's nature conservation and it's not tidy green fields, it's rough looking corners, corncrake corridors full of nettles all the sorts of things that have disappeared... We've had to recreate or allow the ground to go back a little bit. So you can understand why people... think it's strange, and we're doing what we can to explain what we're doing better to people so that they understand what it is that we're all about.

We've realised that people think that these fields are flooding accidentally and it's poor management. It's quite the opposite. Through the consultation process this year we're trying to get it through that every field we have has its own sort of management plan ... Some people think that the floods are full of saltwater from the estuary that has flooded in and that's poisoning the grassland and that's bad management. But it isn't. It's carefully controlled freshwater that's coming down off the hill that's creating this important lowland wet grassland habitat... I think in the south of England if you create habitats like this, the contrast between farmland and the nature reserve is so great in terms of its wildlife that nobody thinks twice about whether you should or shouldn't have done it.

Some of our fields are rushy but a lot of our fields are very green... I think people on Islay know the rest of the island intimately and they know Gruinart intimately and historically. So when they see three fields going to rushes out of thirty fields they just think that's terrible. Those three fields have gone to rushes (and the few fields that are flooded) but it's only a small part of the whole system... And how can our farming be bad when we're producing top quality calves for sale at the local Islay Show and keeping over two hundred and fifty cows?'

You might not think it's bad but they do. And would it be better to try and accept that and to try and sell your farming better to them?

'I think the answer to that question, Andrew, is that all we need to sell better is to get those farmers up here and explain it to them more fully. That's all. And I quote Callum Neill again as an example because he actually worked here. No one could know better than someone who worked here as a dairy hand with Bobby Phillips. And he was quite happy with what he saw. He could see what we'd done to keep up the productivity of this farm in order that we could keep two hundred and fifty cows - that's a huge herd of cattle. If it was bad farming we couldn't produce those calves.

What it's being suggested that farmers do [is] all advertising and hype-new tractors and new machinery and new fertilisers and new crops and everything should be beautifully green and like a computer-generated image of green fields with no weeds in, no wet ditches, no rushes. And I don't blame farmers at all but that is the image that they're constantly force-fed and all we're doing is giving a different image.

But what we're trying to show... the government is that the best way of doing it is by farming it in an environmentally friendly way. And I feel that we're on the same side of the fence as the farmers here really. But they see the small differences such as rushy fields and rush-lined ditches and say, 'that's not farming' but I look at the bigger picture.'

In these passages from my interview with Pete, he showed knowledge of three areas that some farmers had suggested the RSPB were ignorant of. Firstly, he understood and, to an extent, appreciated the history of the site and the manner of its creation. Secondly, he showed that he knew what good farming meant to farmers in Islay and that this was an important contrast that farmers made between the flats as they were under the RSPB 
and the flats as Bobby Phillips had farmed them previously. The fields had been "nice and green" but "the fields now are not nice green fields." Finally, he pointed out that the RSPB understood and used the drainage system that had helped to make the flats such a good farming area. The RSPB had actively maintained, improved and used this system to control water levels for the benefit of both wildlife and farming. In all these cases a contrast between past and present management could be drawn. These differences were explained as being a consequence of the RSPB's nature conservation priorities. Conservation, according to Pete, was "not tidy green fields, it's rough looking corners, corncrake corridors full of nettles all the sorts of things that have disappeared". The appearance of the reserve was borne not of ignorance but of different productive priorities. Furthermore, the break with the past that farmers identified was, in fact, a recreation of a different idea of the past and of what had been meaningful and important then.

The duality of Loch Gruinart as both a nature reserve and farm had proved useful to the RSPB. It enabled an educational message to be conveyed to others about farming 'in an environmentally friendly way'. These others included government, visiting birdwatchers and local farmers such as Callum Neill. In the case of the farmers, the dual identity of the reserve was used to provide 'a different image' from the more pervasive vision of farms that were 'like a computergenerated image'. An area of land that was both farm and nature reserve was the best way of selling this to government, whom it was hoped would provide more money for agri-environment schemes, encouraging more 'environmentally friendly' farming using the sort of methods employed at Loch Gruinart. These changes to farming would potentially remove the status of the reserve as a "unique place... one of the best farmland sites in Scotland... for breeding waders" that was also "producing top quality calves for sale at the local Islay Show and keeping over two hundred and fifty cows" because more farms would be similar to Loch Gruinart. This change had failed to materialise partly because of a lack of money from government but also because farmers saw these "small differences such as rushy fields and rush-lined ditches and [said], 'that's not farming",. So for the RSPB what was crucial was thus a process of education, of explaining their priorities and their understanding of the reserve better so that farmers "understand what it is that we're all about". If farmers on the island had come over, as Callum Neill had done, then the concerns of farmers could be allayed and they would understand the real value and meaning of these "small differences". Through education, conservation could thus be seen as a more negotiable form of change.

But despite these differences, I occasionally encountered some provisional support for the RSPB and their work at Loch Gruinart. One farmer whose land adjoined the reserve was Michael Phillips, the son of Bobby who had farmed at Aoradh prior to the RSPB and who had organised the great improvements on the flats during the 1950s. Michael told me that there was a lot of resentment towards the RSPB over the flats:

'About thirty men worked with my Dad to drain the flats.
A lot of the work was done by hand. All of them say it's their greatest memory of farming, when they finished draining the flats. When you ask them what they think about what the RSPB have done then their faces drop. But then people ask me what I think but it doesn't bother me. The men got paid for it and it's the RSPB's land now.'

Michael added that he was one of the least 'anti-RSPB' farmers around and that the RSPB produced very good quality stock that got top prices at sale. Anthony Scott expressed similar sentiments:

'My father had no time for RSPB or SNH and would have nothing to do with them. But these people are here to stay and there's no use having that attitude forever. Life's too short and I'm young enough to change my ideas. I don't mind working with them, although as a farmer I don't like what they do with their farm because it looks like bad farming. But it doesn't really bother me because at the end of the day it's their land and they can do what they like with it. I might be bothered if they had loads of thistles and docks and ragwort and it was spreading onto my land but I don't understand why people take it so personally. Farmers come by my farm and they start asking me all sorts of questions like, 'Why did you take that wall down?' I'm tempted to answer, 'Because it's my land and I can do what I like with it.' That's more the sort of normal attitude in England but not so much up here.'

In both cases, the farmers seemed at pains to reduce the significance of what the RSPB did with their land. Whilst they noticed this, it was only of concern to the RSPB and its members. Even though both they and others might have perceived the reserve as bad farming this did not represent anything more than the RSPB having a different agenda that they were at liberty to pursue, just as any farmer should be allowed to do as they wished with their land. For Anthony and Michael the difference between farmers and conservationists was secondary to the rights of individual owners and occupiers to follow their own priorities. It was not their place to determine what a neighbour should do with their land because it was not a type of interference that they would welcome themselves. Even the letter-writing 'very irate farmer' desired only to influence the RSPB indirectly, through the establishment of proper "accountable" relations between the Society and government.

\section{CONCLUSION}

Throughout these narratives of the Loch Gruinart reserve, knowledge and ignorance have been invoked. Farmers suggested that the RSPB were ignorant of how to farm and of the history of the site. They did not even take the trouble to learn these things from the farmers who had relevant knowledge. All of these deficiencies were evident to farmers because they knew that floods, rushes, bad grass, weeds, rabbits and nettles were indicative of a bad farm and went against the ethic of a productive relationship with the land. The RSPB thought that farmers were ignorant of certain aspects of the reserve 
management and so they needed to educate them in order that they knew why the things that were done on the reserve were so important. Pete seemed well aware that the farmers saw the RSPB as being ignorant but some of the farmers also implied that the RSPB considered farmers themselves to be ignorant of farming. These ideas of knowledge difference were powerful rhetorical devices, although it is far harder to assess whether they were informed by anything more concrete. What is clearer is that farmers and the RSPB situated themselves differently in relation to the landscape of Loch Gruinart and that this diversity of opinions was promoted through the duality of the farm/nature reserve. The reserve thus became a metaphor of the interaction of farming and conservation, the differences and connections between them and the trajectory that relations between farmers and conservationists followed. So long as there remained the "small differences", of which both farmers and the RSPB were acutely aware, then both the ambiguities and the symbolic freight of the reserve endured as a means of negotiating and representing ideas about farming, conservation and their practitioners.

The duality of the farm/nature reserve presented both an opportunity and a problem for the RSPB: to be a reserve required that Loch Gruinart was different to a farm but this also made it harder for farmers to take their approach to managing the land seriously. The RSPB wanted to offer 'a different image' to farmers, otherwise the reserve would simply have been another farm and would not have carried any distinctive message. As conservationists they faced the dilemma of encouraging farmers to change how they farmed without alienating them and whilst still expressing their own, necessarily different, position. The reserve was not so much a ghetto of nature (cf. Campbell 2005: 283) within Islay but it was seen by the RSPB as a repository of traditional landscape features that were disappearing from other places within the UK, and to some extent from Islay (Jedrej and Nuttall 1995: 138). The debates over the appearance of the reserve and the RSPB's management of the land were rooted not in contestations over access to resources but in perceived divergences in the appearance of the landscape that were understood to be rooted in different kinds of relation: with place, with people and with the past and future. The temptation would be to style these differences as being founded on the conservationists' concern with nature and the farmers' concern with society and social relations (cf. Ingold 2005 502). From this would follow the conservationists' retrospective tendency, concerned with a more natural past in which human influence on the landscape was less, and the farmers' prospective tendency to look forward, to improve their land and produce more. But I argue that the reserve provides a means to discuss conservation and farming in Islay as different, but overlapping, means of dwelling (Ingold 2000, 2005), in which my interlocutors were situated, both by themselves and others, within particular fields of relations.

Finally, one might speculate on why a wealthy conservation charity should be at all concerned over the opinions that others hold of their management practices. It should be noted that whilst the RSPB's attempts to educate others about their work at Loch
Gruinart had the overt political aims of influencing others to follow their example, it also had depoliticising aims. This was to make the management of the reserve seem like 'common sense', to seem entirely normal and legitimate to any rational person. It could then be demonstrated that the RSPB were acting only in the apolitical interests of wildlife and were not striving to question or threaten the activities of other people (Latour 2004). The fact that the controversy of the reserve could be seen by the RSPB as a problem was perhaps a result of a misapprehension of what conservation is or should be about. Conservation, I would argue, is not so much a concern with the apolitical interests of biodiversity but is an act of bringing non-humans into the political arena, which inevitably and productively produces 'complications and controversies' (Latour 2004: 37). Like any attempt at consensual conservation, this case elicited political realignments and negotiations, of which the Loch Gruinart reserve was an integral part. It is only by going through this complicated process of situating that conservation could become a part of the place in the same way that farming is.

\section{Notes}

1. Fieldwork was conducted in Islay as part of the author's doctoral research at the University of St Andrews between May 1999 and September 2000, with four subsequent visits between 2002 and 2005. The material discussed within this chapter was part of a larger ethnographic study of relations between conservation organisations and farmers in Islay.

2. See Mackenzie (1998) for an example of shared symbols of community being deployed in an environmental dispute in western Scotland.

3. Ileach Vol. 24 No. $2411^{\text {th }}$ October 1997.

4. The names of all informants have been changed to pseudonyms, which was decided before conducting interviews.

5. Environmentally Sensitive Area - a designation enabling funding for ecologically sensitive farming.

6. Ileach Vol. 24 No. $2525^{\text {th }}$ October 1997.

7. A farmer who had previously worked at Aoradh when it was a dairy farm.

\section{REFERENCES}

Bateson, G. 1979. Mind and nature: A necessary unity. Cresskill: Hampton Press.

Bender, B. 2001. Introduction. In: Contested landscapes: Movement, exile and place (eds. Bender, B. \& M. Winer). Pp. 1-18. Oxford: Berg.

Brosius, J.P. 1999. Analyses and interventions: Anthropological engagements with environmentalism. Current Anthropology 40(3): 277-309.

Campbell, B. 2005. Introduction: Changing protection policies and ethnographies of environmental engagement. Conservation and Society 3(2): 280-322.

Cohen, A.P. 1982a. Belonging: Identity and social organisation in British rural cultures. Manchester: Manchester University Press.

Cohen, A.P. 1982b. Belonging: The experience of culture. In: Belonging: Identity and social organisation in British rural cultures (ed. Cohen, A.P.). Pp. 1-17. Manchester: Manchester University Press.

Cohen, A.P. 1985. The symbolic construction of community. London: Routledge.

Cohen, A.P. 1987. Whalsay: Symbol, segment and boundary in a Shetland island community. Manchester: Manchester University Press.

Cohen, A.P. 1994. Self consciousness: An alternative anthropology of identity. London: Routledge. 
Cohen, A.P. 1996. Personal nationalism: A Scottish view of some rites, rights, and wrongs. American Ethnologist 23(4): 802-815.

Cronon, W. 1996. The trouble with wilderness: Or, getting back to the wrong nature. In: Uncommon ground: Rethinking the human place in nature (ed. Cronon, W.). Pp. 69-90. London: W.W. Norton.

Einarsson, N. 1993. All animals are equal but some are cetaceans: Conservation and culture conflict. In: Environmentalism: The view from anthropology (ed. Milton, K.). Pp. 73-84. London: Routledge.

Elliott, R.E. 1989. The birds of Islay. London: Christopher Helm.

Evans, D. 1997. A history of nature conservation in Britain. London: Routledge.

Hobart, M. 1993. Introduction: The growth of ignorance? In: An anthropological critique of development (ed. Hobart, M.). Pp. 1-30. London: Routledge.

Ingold, T. 2000. The perception of the environment: Essays on livelihood, dwelling and skill. London: Routledge.

Ingold, T. 2005. Epilogue: Towards a politics of dwelling. Conservation and Society 3(2): 501-508.

Jedrej, C. and M. Nuttall. 1995. White settlers: The impact of rural repopulation in Scotland. Chur, Switzerland: Harwood Academic Publishers.

Latour, B. 2004. Politics of nature: How to bring the sciences into democracy. London: Harvard University Press.

Littlejohn, J. 1963. Westrigg: The sociology of a Cheviot parish. London: Routledge and Kegan Paul.

Macdonald, S. 1997. Reimagining culture: Histories, identities and the Gaelic renaissance. Oxford: Berg.

Mackenzie, A.F.D. 1998. The Cheviot, the stag and the white, white rock? Community, identity and environmental threat on the isle of Harris. Environment and Planning D: Society and Space 16: 509-532.

Mazzullo, N. 2005. Environmental conservation and local interests in Finnish Lapland. Conservation and Society 3(2): 388-406.

Mewett, P.G. 1982a. Associational categories and the social location of relationships in a Lewis crofting community. In: Belonging: identity and social organisation in British rural cultures (ed. Cohen, A.P.). Pp. 101-130. Manchester: Manchester University Press.

Mewett, P.G. 1982b. Exiles, nicknames, social identities and the production of local consciousness in a crofting community. In: Belonging: Identity and social organisation in British rural cultures (ed. Cohen, A.P.). Pp. 222-246. Manchester: Manchester University Press.

Milton, K. 1996. Environmentalism and cultural theory. London: Routledge.

Milton, K. 2000. Ducks out of water: Nature conservation as boundary maintenance. In: Natural enemies: People-wildlife conflicts in anthropological perspective (ed. Knight, J.). Pp. 229-246. London: Routledge.

Novellino, D. 2003. Contrasting landscapes, conflicting ontologies. In: Ethnographies of conservation: Environmentalism and distribution of privilege (eds. Berglund, E. and D.G. Anderson). Pp. 171-188. Oxford: Berghahn Books.
Nygren, A. 2003. Nature as contested terrain: Conflicts over wilderness protection and local livelihoods in Rio San Juan, Nicaragua. In: Ethnographies of conservation: Environmentalism and distribution of privilege (eds. Berglund, E. and D.G. Anderson). Pp. 33-49. Oxford: Berghahn Books.

Ogilvie, M.A. et al. 1999. Barnacle goose Branta leucopsis: Greenland. In: Goose populations of the Western Palearctic: A review of status and distribution (eds. Madsen, J. et al.). Pp. 246-256. Ronde, Denmark: National Environmental Research Institute.

O'Neill, J. 2005. Environmental values through thick and thin. Conservation and Society 3(2): 479-500.

Patton, D.L.H. and J. Frame. 1981. The effect of grazing in winter by wild geese on improved grassland in West Scotland. Journal of Applied Ecology 18: 311-325.

Phillips, S.K. 1986. Natives and incomers: The symbolism of belonging in Muker parish, North Yorkshire. In: Symbolising boundaries: Identity and diversity in British cultures (ed. Cohen, A.P.). Pp. 141-154. Manchester: Manchester University Press.

Rapport, N. 1993. Diverse world-views in an English village. Edinburgh: Edinburgh University Press.

Richards, E. 2000. The highland clearances: People, landlords and rural turmoil. Edinburgh: Birlinn.

Satterfield, T. 2003. Anatomy of a conflict: Identity, knowledge and emotion in old-growth forests. Vancouver: University of British Columbia Press.

Smout, T.C. 2000. Nature contested: Environmental history in Scotland and northern England since 1600. Edinburgh: Edinburgh University Press.

Storrie, M. 1981. Islay: Biography of an island. Port Ellen: The Oa Press.

Strathern, M. 1981. Kinship at the core: An anthropology of Elmdon a village in north-west Essex in the nineteen-sixties. Cambridge: Cambridge University Press.

Strathern, M. 1982a. The place of kinship: Kin, class and village status in Elmdon, Essex. In: Belonging: Identity and social organisation in British rural cultures (ed. Cohen, A.P.). Pp. 72-100. Manchester: Manchester University Press.

Strathern, M. 1982b. The village as an idea: Constructs of village-ness in Elmdon, Essex. In: Belonging: Identity and social organisation in British rural cultures (ed. Cohen, A.P.). Pp. 247-277. Manchester: Manchester University Press.

Strathern, M. 1984. The social meaning of localism. In: Locality and rurality: Economy and society in rural regions (eds. Bradley, T. and P. Lowe). Pp. 181-198. Norwich: Geo Books.

Warren, C. 2002. Managing Scotland's environment. Edinburgh: Edinburgh University Press.

Whitehouse, A. 2004. Negotiating small differences: Conservation organisations and farming in Islay. PhD thesis, University of St Andrews, Scotland.

Whitehouse, A. In print. How the land should be: Narrating progress on farms in Islay, Scotland. In: Landscapes beyond land: Routes, aesthetics, narratives (eds. Arnason, A. et al.). Oxford: Berghahn. 